\title{
The Word Yeghern and the Semantic Field of Its Equivalence in English
}

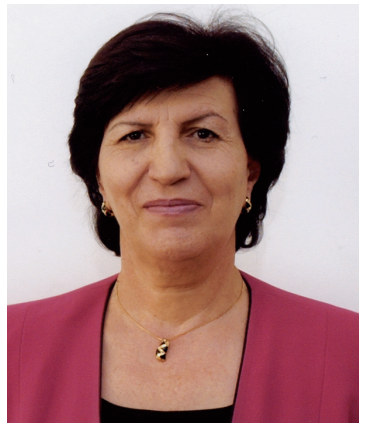

Seda Gasparyan
In the beginning was the Word, and the Word was with God, and the Word was God.

(John 1.1)

$\mathrm{T}$ he vocabulary of a language is the richest repository, in fact, the most reliable criterion of its wealth. It is through words that one gets to know and to explore the surrounding world, that one learns to think, to express one's thoughts and concerns, emotions and experiences. And since words undergo semantic changes over the centuries, reflecting a variety of social, historical and political impacts as well as that of everyday life, their appropriate choice in speech making acquires utmost importance. In Maupassant's words, "no matter what you are going to talk about, there is only one word you can express it by, only one adjective you can describe it with, only one verb to animate it with. ... thus, one must look for that very noun, that very adjective and that very verb....."

The meaning of a word may broaden as the word becomes richer and richer under the influence of various linguistic and extralinguistic factors, acquiring new semantic meanings and shades of meanings, new expressive-emotional-evaluative overtones. The word may grow in depth and width, and become more capacious both semantically and stylistically, thus expressing "a whole world". ${ }^{2}$ This is clearly evident in speech whenever an "inanimate unit" of language revives, becomes more dynamic and presents the speaker's emotional attitude in a condensed way. ${ }^{3}$

The issues associated with such an intricate unit of language become even more complicated when one tries to reproduce a word adequately using the linguistic means of another language, i.e. to overcome the obstacles posed by multilingualism in the path of mutual recognition and understanding between nations.

In our analysis of this question below an attempt will be made to study the semantic field of equivalence of the Armenian word yeghern (knknG) and the problem of its adequate translation into English.

\section{The semantic structure of yeghern (knkna)}

As an initial stage in our investigation, however, it is necessary to clarify the semantic structure of the lexical unit in Armenian. The "Fundamental Etymological Dictionary of the Armenian Language" ${ }^{4}$ by Hrachia Acharyan presents the opinion of the great linguist Sophus Bugge who claims that the Armenian words yeghern, yegher, yeghuk (knting, tinkn, tinnıl) originate from the root $\mathrm{gel}$ in the Indo-European protolanguage. 
Comparison with "quelan" in Old High German, "quellian" in Saxon, and "cwelan" - kill ${ }^{5}$ in Old English makes it quite clear that the underlying meaning of all these words is to kill, to commit a crime. A. Sukiasyan suggests a whole range of synonyms in his

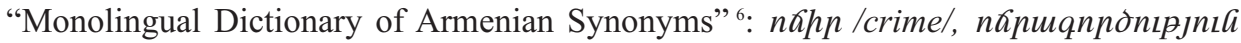

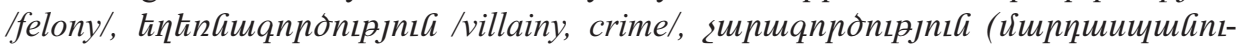

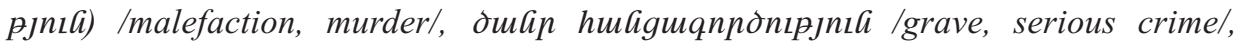

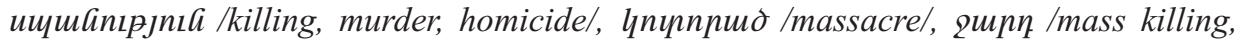

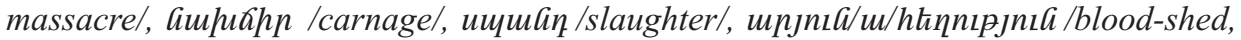
carnage, massacre/, иршдпьрјnıl /massacre, butchery, slaughter/, juршпша /killing with a Turkish dagger/, hnnhnnnuर /killing cruelly, butchery, slaughter/, inknanıpjnıl/hag.//harm, malice, rascality/, ghnuuuuanıpjnıa/genocide/. These are not absolute synonyms, of course, but they all have the semantic constituent to kill (i.e. to commit a crime) in their semantic structure.

A study of the data presented in Armenian-English dictionaries ${ }^{8}$ provides the following explanations of the word yeghern (hqhnG): crime (nאhn), misdemeanor (zwn

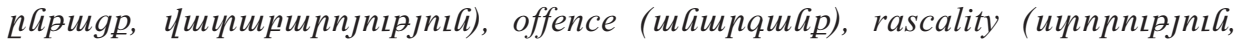

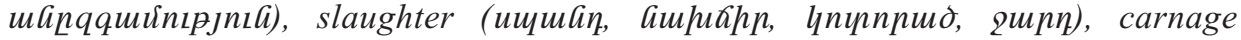

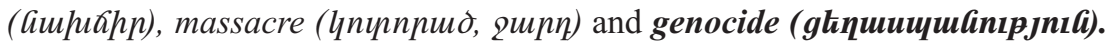

In this comprehensive field of synonyms one can trace similarities as well as obvious differences. For example, the word crime is defined as an act (usu. grave offence) punishable by law; evil act; such acts collectively $\left(\operatorname{COD}^{9}: 242\right)$; an act committed in violation of law forbidding or commanding it, and for which punishment is upon conviction (HINDEL : 313), while the word misdemeanor is used to mean an action, which though being punishable by law, is not so grave or serious as, for instance, stealing or murder (LDCE). The presence of the semantic constituent of crime in the lexical units offence (attacking, aggressive action - COD) and rascality (dishonest behaviour - LDCE), may be said, not to be always obvious. The intention of an offence in the sense of aggression or dishonest behaviour is not necessarily accompanied by murder. While "the modern tendency is to refer to crimes as offences" (ODL, p. 317), and the words offence and rascality carry a negative inherent connotational overtone, this is presented with far less force than in the lexical unit crime. As far as the definitions of the words slaughter (the killing or slaying of people in large numbers - OED), carnage (the slaughter of a great number, esp. of men; butchery, massacre - OED), massacre (the indiscriminate, merciless killing of a number of human beings - WNWD) are concerned, they are relatively closer in meaning to yeghern (knknG) and the prevalent constituent in their semantic structure is crime (criminal act not conditioned by a lawful necessity).

Genocide is a comprehensive term, and its semantic structure is the most inclusive. Among the interpretations suggested by various monolingual English dictionaries, the one proposed by the WTNID seems to be the most complete from the point of view of the semantic globality of the word: the use of deliberate systematic measures /as killing, bodily or mental injury, unlivable conditions, prevention of birth/ calculated to bring about the extermination of a racial, political, or cultural group, or to destroy the language, religion or culture of a group. The fact that this lexical unit was introduced into different 
fields of humanitarian research only after the 1940s is accounted for by the chronology of its occurrence.

The word genocide was first coined in 1943 by Raphael Lemkin - a Polish-Jewish lawyer, who, in one of his articles ("Crime of Barbarity") used the word with reference to the massacre of the Armenians in the Ottoman Empire in 1915 and interpreted genocide as a crime against international law. ${ }^{10}$ Later he defined genocide as any act which is carried out with the aim of partial or total annihilation of any national, ethnic, racial or religious group as such and, with the encouragement of the United States, he submitted his definition to the UN General Assembly for consideration. Much later, on December 9, 1948, the UN adopted the Convention on "the Prevention and Punishment of the Crime of Genocide" and Lemkin's definition served as the basis for Article II of the Convention. ${ }^{11}$

The word genocide originates from the Latin gens, gentis (origin, race, gene/biolog/, type) or the Greek genos (with the same meaning) and the Latin lexical unit cidium (cutting; killing) which entered the English language through French as cide (the act of killing).

\section{Adequate translation}

Coming to the problem of adequacy, terminological dictionaries offer three different definitions of the term translation. ${ }^{12}$ At the emic level and in the field of lexicography in particular, translation is defined as the juxtaposition of two or more languages, with the object of tracing semantic similarities between the units of those languages. In other words, translating means finding elements in the target language which are capable of conveying the semantic contents of the source language words adequately.

The study of the aforementioned dictionary data shows that the word as a meaningful unit not infrequently presents a complex structure, and since there can almost never be absolute coincidence of the minimal distinctive semantic features operating in the semantic structures of different lexical units, we can never speak of absolute synonymy. Each of the smallest elements making up the content plane of the meaning of a word may be realized through varying applications of the same word depending on the speech situation. It is here that the well-known language/speech dichotomy, ${ }^{13}$ which is of fundamental significance in linguistics, should not be underestimated. This proposition makes it possible to regard the problem of adequate translation as a dialectical correlation of equivalence at the level of language, and equivalence at the level of speech. This, however, does not imply at all that the only precondition for finding the equivalent unit is to examine the original context and the speech situation. The first step in this process is to establish those constituent elements of the target language system which, irrespective of the context and the speech situation, are always equivalent to the corresponding units of the source language. In other words, the first step is to achieve semantic equivalence. The basic and most reliable sources of information for language adequacy are, undoubtedly, monolingual dictionaries, and dictionaries of synonyms that are based on the results of study of the semantic constituents of the meanings of words. 
In the semantic field of equivalence of the word yeghern (knkna), crime may be viewed as a non-differentiated unit, as the meaning it expresses is general and can be traced in nearly all the units in the field. The variants slaughter (mass killings, execution, massacre), carnage (massacre, bloodshed, butchery), massacre (mass murder, annihilation, huge loss of life following disease) are considerably closer to yeghern (hnhnG). They nevertheless emphasize different semes contained in the semantic structure of the word in question, while the complete and global picture of the phenomenon is reflected in the word-unit genocide. However, the context plays a highly important role in the adequate choice of the equivalent word. Full equivalence is attained where there is not only semantic, but also functional-stylistic and pragmatic adequacy, i.e. when the target language unit (a word, a sentence, a text, etc.) is equivalent to the source language unit in all the semantic, stylistic and pragmatic values that this carries. And although the semantic constituent is of prime importance, and the basic function of translation, i.e. interlingual communication, will not be realized, unless semantic adequacy is achieved, the role of the other constituent elements in achieving the desired adequacy is of no less significance. The reason for this is that it is in a particular context and in a certain speech situation that words, under the influence of various linguistic and extralinguistic factors, take on additional semantic and stylistic overtones and carry diverse pragmatic meanings.

\section{Contextual realizations of the meaning expressed by yeghern (kqlina)}

An attempt will now be made to look into several different contextual realizations of the meaning expressed by the Armenian word yeghern (knknG).

If nations are allowed to commit genocide with impunity, to hide their guilt in a camouflage of lies and details there is a real danger that othebutal regimes will be encouraged to attempt genocides. Unless we speak of the Armenian genocide and unless the Government recognizes this historical fact, we shall leave this century of unprecedented genocides with this blot on our consciences.

\section{Caroline, Baroness Cox}

House of Lords, 4/1/1999 ${ }^{14}$

In the extract adduced above the speaker voices a deep concern that by failing to recognize the Armenian Genocide openly we may abet similar atrocities on the part of other regimes. If nations are allowed to commit genocide and get away with it, covering up their sin with a veil of lies and denials, our age may turn into a period of continuing genocides.

The passage is rich in a number of units carrying negative connotations (commit genocide, impunity, hide the guilt in a camouflage of lies and denials, danger, brutal regimes, unprecedented genocides, blot), the combination of which in this context reveals the negative attitude of the speaker towards those who turn a blind eye to the Armenian Genocide, let alone perpetrate it or any other genocide. Baroness Cox is con- 
vinced that if the Armenian Genocide fails to be recognized as such, Mankind will always have to bear this blot on its conscience.

The application of the word genocide in this small passage more than once is intended to warn the listener against the scale and the disastrous nature (a real danger) of this possible threat to humanity as a whole, to open the eyes of those who play a key role in the discussion of this issue, and to induce them to be honest and just.

The next passage is taken from the speech of John Evans, the former US Ambassador to Armenia, addressed to the Armenian community in America.

Today I will call this Armenian genocide. I think that we, the US government, owe you, our fellow citizens, a more straightforward and honest discussion of this problem. I can tell you as a person who has studied this problem - I have no doubts about what happened. I think that it is inappropriate for us, the Americans, to play with words in this case. I believe that we must call a spade a spade.

\section{John Evans \\ US Ambassador to Armenia Addressed to American Armenians on February 19, $2005^{15}$}

The context of the passage obviously differs from the previous one with respect to its emotional-expressive charge. Stylistically neutral units are dominant here (US government, fellow citizens, straightforward discussion of the problem, tell, a person who has studied this problem, about what happened, etc.). Their presence in the extract indicates that the goal of the speaker is to present to the public the firm belief to which he has come on the basis of his own thorough investigation of the historical evidence, according to which the massacre of the Armenians committed by the Ottoman Empire was nothing but genocide.

Here, the speaker does not set out to influence the listener by inflaming his/her wounds, which are still fresh. His speech is based on the truth he has arrived at after his own examination of the historical facts (as a person who has studied this problem). The use of idiom (to call a spade a spade) in this speech is of core importance. On the one hand, it confirms that the word genocide is the most appropriate in the light of evaluation of the events as such, and on the other hand, it implies a plea to leave political considerations aside and to call the phenomenon of the Armenian Genocide by the word that equates to it internationally, i.e. genocide.

The text presented below is the appeal of 68 professionals representing various spheres of activity sent to the Swedish Parliament in 2008.

The Armenian Genocide, which also engulfed the Assyrians, Pontic Greeks and other minorities in the Ottoman Empire, began more than nine decades ago in 1915, but this issue gains added urgency the longer that denial of the crime continues. The genocide, or "extermination" as it was labeled by the international media and diplomatic corps, was an estab- 
lished fact for the world community. During the brief postwar period following the defeat of Turkey in 1918 until the rise of the Turkish Nationalist movement led by Mustafa Kemal, the annihilation of the Armenians was discussed openly. Turkish court martial tribunals tried political and military leaders implicated in "war crimes" and "crimes against humanity". Several of the accused were found guilty and were sentenced to death or given prison terms. Postwar Turkey passed through a phase similar to that of Germany after World War II. During these proceedings the truth about the persecution of the minorities in the Ottoman Empire was brought to light with horrifying details.

The process did not last long, however. The rise of the Turkish Nationalist movement ad rejection of the Sultan's government ultimately led to the disbanding of the tribunals and the release of most of the accused. Almost all of the remaining Christian population-Armenian, Assyrian and Greek - was then cleansed from their homelands of several millennia. Much of the court data and protocols disappeared, and Turkey entered a period of trying to erase all traces of Armenian existence in Anatolia and the historic Armenian plateau to the east.

Nine decades later, the once called "forgotten genocide" is no longer forgotten and warrants growing attention among academic and political circles. It is seen as a prototype of mass killing in the twentieth century and can be viewed as one of the most successful campaigns of genocide and ethnic cleansing in all history. The victimization of the Armenians extended to the Assyrian, Greek, Yezidi and even Kurdish population, which was subjected to extensive "social engineering" through forced relocation and resettlement. As it happened, the Turkish beneficiaries of an "Armenia without Armenians" and, despite worldwide pledges and promises to punish the perpetrators, escaped any responsibility for the crime. Today, Turkey implements an active campaign of denial. Silence and passivity on the part of the world community, including Sweden, can only aid an abet this campaign. All the arguments relating to the need to further research or lack of consensus among scholars are spurious. The archives of every major country in Europe leave no doubt about the campaign of annihilation which occurred under the cover of a world conflict. The denialist arguments are all politically motivated and have nothing to do with the historical record. They are more credible than those of Holocaust deniers such as Robert Faurisson, David Irving, Willis Carto, and Ernst Zundel.

Raphael Lemkin, who coined the term genocide in the 1940s and was the principal author of the U.N. Convention on the Prevention and Punishment of the Crime of Genocide, was deeply aware of the Armenian calamity and the failure of the international community to intercede or at least to punish the authors of the genocide. Recent research has demonstrated how deeply he was affected by the absence of effective internation- 
al machinery to intervene at the times. He was also troubled by the persecution and massacres of the Assyrians in Iraq during the 1930s. What is more, newly conducted research at Uppsala University confirms that the Swedish Foreign Department and Government, through the reports of Ambassador Per Gustaf August Cosswa Anckarsvard's and Military Attache Einar af Wirsen, were well aware of the annihilation that was occurring in the Ottoman Empire.

Today Sweden is internationally regarded as a champion of human rights. It is incumbent on the Swedish authorities to live up to this reputation and to reject any compromise with negationism and denial. The Swedish Government should attempt to assist Turkey to become a better democracy by facing its history and acknowledging the truth, not by continuing to stagger in the darkness of self-deception and pretense. Today, the data and information about the Genocide are so extensive that no serious politician can honestly cite insufficient or inconclusive research as an excuse to avoid recognition. Refusal to recognize established fact based on qualitative and quantitative research may be regarded as being tantamount to denial. The researchers have done their job in establishing the reality of the Armenian Genocide. Now, the turn has come for the political leaders to fulfill their responsibility by recognizing this calamity for what it was.

The signatories of this letter do not consider there is any doubt that the massacres of Christians and other minorities in the Ottoman Empire during the World War I constituted genocide. Even though research must and will continue, the existing information is compelling and must be acknowledged as such ${ }^{16}$.

This appeal, based on documentary data, is meant to voice the firm belief of the signatories that the recognition of the Armenian Genocide is the most honest, just and indeed the only way to avoid the necessity of finding an excuse for turning a blind eye to what the world community now regards without doubt as an established truth. It is also the best way to help Turkey put an end to its decades of self-deception, to evaluate its history as it is and to move more steadily towards democratization. Post-war Turkey witnessed a few attempts at consideration and condemnation of the most dreadful and awesome persecutions, carried out by the Ottoman Empire in ways beyond human imagining, labeling them war crimes. However, the process did not last long. With the Turkish Nationalists gaining more power, the courts were closed, many of the convicts were set free and many of the court protocols and documents reflecting the truth disappeared. But are we aware of the fact that Armenians were not the only nation sacrificed on the altar of Turkey? There were also Assyrians, Greeks, Yezidis and even Kurds. Moreover, the truth is that despite the pledges and promises the international community gave to the people of Armenia, the crime remained unpunished. Today Turkey has launched an even stricter campaign of genocide denial. Silence and passivity will only encourage this campaign of lies. And all the arguments about lack of agreement in academic circles and the 
need to continue research in order to clarify the issue, are nothing but false and simulated. The archives piled up in different European countries are sufficient to prove that what is labeled a consequence of war was, in fact, a campaign of extermination of an entire nation.

The context of the appeal addressed to the Swedish Parliament is of great interest in the sense that almost all the constituents making up the semantic whole of the word genocide (extermination, crime, ethnic cleansing, cleanse from their homelands of several millennia, victimization, forced relocation and resettlement, campaign of annihilation, mass killing, massacre) are introduced through different linguistic units. Despite its apparent informative, documentary nature from the point of view of pragmatics, the passage is not devoid of certain elements typical of public writing, including units with emotive-expressive-evaluative overtones. This is accounted for by the fact that the speech is designed to win over others to the attitude of the Swedish Parliament, to awaken the international community from the deep sleep of indifference towards human destinies, and to arouse a wish to be just and honest in the approach to the question.

Apart from the aforementioned units which are of exceptional interest as objects of our study and all carry an inherent negative connotational value, the passage as a whole is drenched with negative evaluative overtones both in its verbal, horizontal context and in the denial of the historical and political events condensed between the lines (i.e. the vertical context) (accused, guilty, sentenced to death, persecution of the minorities, horrifying details, much of the court data and protocols disappeared, a period of trying to erase all traces of Armenian existence in Anatolia, the victimization of the Armenians extended to Assyrian, Greek, Yezidi and even Kurdish population, "social engineering" through forced relocation and resettlement, Turkish authorities became the beneficiaries of an "Armenia without Armenians", .... escaped any responsibility for the crime, etc.)

The use of the word combination social engineering which also has a terminological value, should be singled out for having no connection with the general context. ${ }^{17}$ It creates a kind of stylistic contrast with the help of the trope of enantiosemy and acquires an obvious ironical meaning. The role of inverted commas in the realization of this stylistic device of irony should also be noted. The pragmatic goal of the authors' intention is made clear through the combination of all these linguostylistic devices, which are intended to present the true picture of the genocide committed at the very start of the $20^{\text {th }}$ century and to show the abhorrence of such anti-human acts by the progressive peoples of the world. The supporters of the appeal hold to a firm belief that the Swedish Parliament will find a place among those representatives of progressive nations.

Surely enough, the Swedish Parliament recognized the Armenian Genocide on March 11, 2010, as well as the act of the annihilation of Assyrians and Pontic Greeks, thereby proving the efficiency of this appeal.

The word calamity (unkin) used in this context may be characterized as a lexical unit with an extremely general and non-differentiated semantic meaning. From a study of the wide array of synonyms of calamity in dictionaries of English synonyms ${ }^{18}$ (1. trouble, distress, misfortune, misery, unhappiness, affliction; 2. referring to an instance of what is calamitous: trouble, misfortune, misery, distress, disaster/implying unforeseen 
and adverse forces/, catastrophe /with implications of finality/, blow, scourge /implies severe and continued calamity/; curse/spec./ fatality) the following conclusion may be drawn: although any tragedy or evil, including wars, massacres and devastations may be termed a disaster in the broadest sense, ${ }^{19}$ the word calamity appears unable to convey the global meaning of the Armenian Genocide in all its manifestations.

\section{Conclusion: the adequate English equivalent of yeghern (knkna).}

The results of the research may be summed up through the following diagram.

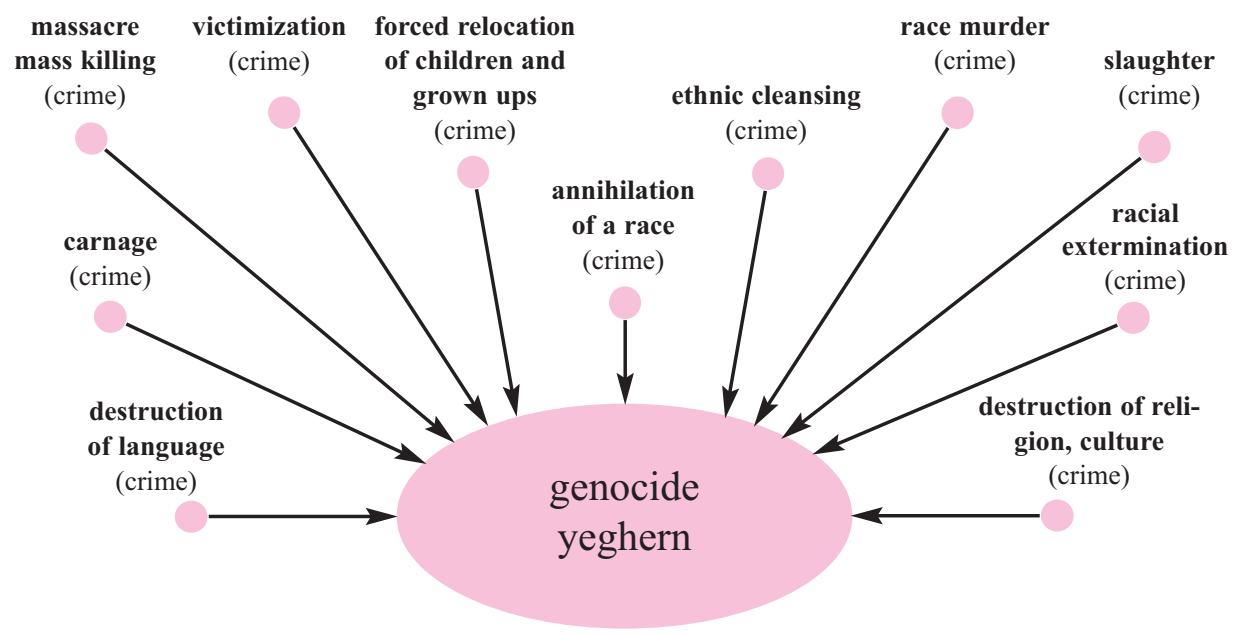

Hence, the study of the word yeghern (knkna) in Armenian and the examination of its semantic, stylistic and pragmatic fields of equivalence in English at both language and speech levels reveal that the English equivalent for the Armenian word yeghern is genocide - the only unit acknowledged internationally and used within the scope of international law. ${ }^{20}$

\section{Notes:}

1. See Guy de Maupassant, Etude prefacant le livre Lettre à George Sand; par Gustave Flaubert. Paris: G. Charpentier et Cie; 1884. http://flaubert.univ.rouen.fr/bovary_ 6/temoins/guy2.html

2. The qualification offered by Toumanian is quite well-known. See R. Ishkhanyan, Arevelahay banasteghtsutyan lezvi patmutyun (The history of the language of Eastern Armenian poetry). Yerevan: Yerevan University Press, 1978.

3. See Paruyr Sevak, Sayat Nova. Yerevan, 1987, p.136. In the poetic speculations of Razmik Davoyan "Gishakerneri, antaghandneri strukn e Bary/ Na Hantcharin e 
miayn havasar" (The word is a slave of beasts, the untalented/ It is equal only to the Genius). R. Davoyan, Bary (The Word)// Meghrahats. Yerevan: Hayastan Press, 1973, p. 15.

4. Hr. Acharyan, Hayeren armatakan bararan (Fundamental Etymological Dictionary of the Armenian Language). Yerevan: Yerevan University Press, 1973, Vol.2, p.17.

5. See A.I. Smirnickij, Khrestomatiya po istorii anglijskogo jazyka. Moscow: Literatury na inostrannykh jazykakh Publ., 1953, p. 160.

6. See A. Suqiasyan, Hayots lezvi homanishneri batsatrakan bararan (Explanatory Dictionary of Armenian Synonyms). 2nd edition, Yerevan, YSU Press, 2009, p. 264.

7. For thorough examination of the word yeghern see P. Meitikhanyan, Yeghern bari lezvakan qnnutyn (Linguistic analysis of the word yeghern), Pan-Armenian journal Vem: Yerevan, 2009, No. 1(26), p. 144-147.

8. See M. Guyumtchean, Yndardzak bararan hayerene angleren (Armenian-English Extended Dictionary). Peyrut: Atlas, also N. Baratyan et al., Armenian-English Dictionary. Yerevan: Macmillan Armenia, 2002.

9. The following explanatory dictionaries have been used in the article: The Concise English Dictionary (COD). Oxford: Oxford University Press, 1976; The Heritage Illustrated Dictionary of the English Language (HIDEL). New York, 1973; Longman Dictionary of Contemporary English (LDCE). G.B.: Longman Group, 1978; The Oxford Dictionary of Law (ODL). Oxford: Oxford University Press, 4th ed., 1997; The Oxford English Dictionary (OED). Oxford: Clarendon Press, 19611970, V. II; Webster's New World Dictionary (WNWD). Cleveland \& New York: The World Publishing Comp., 1951; Webster's Third New International Dictionary (WTNID). Springfield, Mass.: Merriam-Webster Inc., 1981.

10. In 1944 the US saw the publication of Axis Rule in Occupied Europe by Lemkin in which the author came up with a thorough and detailed legal analysis of the policy of the Nazi Germany during World War II. The work is also noted for the scrupulous examination and further addition to the comments on the term genocide. http://en.wikipedia.org/wiki/Genocide

11. In the present convention, genocide means any of the following acts committed with the intent to destroy, in whole or in part, a national, ethnic, racial or religious group as such: $a /$ killing members of the group; b/ causing serious bodily or mental harm to members of the group; c/ deliberately inflicting on the group conditions of life calculated to bring about its physical destruction in whole or in part; $d$ / imposing measures intended to prevent births within the group; e/ forcibly transferring children of the group to another group. (See Convention on the Prevention and Punishment of the Crime of Genocide, Article II).

12. See O.S. Akhmanova, Slovar' lingvisticheskikh terminov. Moscow, Sovetskaya Entsiklopediya Press, 1966.

13. See A. I. Smirnitskij, Ob'yektivnost'sushchestvovaniya yazika. Moscow, MGU, 1954.

14. www.genocide1915.info/quotes/ 
15. http://www.genocide-museum.am/eng/quotations.php

16. itwasgenocide.armenica.org

17. The WTNID English Dictionary interprets the terminological combination of "social engineering" as manipulation of human resources to affect the role and the function human beings have in society.

18. See Webster's New Dictionary of Synonyms. Springfield, Mass.: Mirriam-Webster Inc. Publishers, 1984; Sturges, Allen, Synonyms and Antonyms. Maud Publication, 1994.

19. See Ed. Aghayan, Ardi hayereni batsatrakan bararan (Explanatory Dictionary of Contemporary Armenian). Yerevan: Hayastan Press, 1976, Vol. 1.

20. The present research allows us to conclude that when uttering the phrase "the Medz Yeghern" in his speech on April 24, 2009, referring to the events carried out in the Ottoman Empire in 1915, the US President Barack Obama was well aware of the equivalence of these units/ http://www,whitehouse.gov/the-press-office/

The logically grounded development of this event, must naturally, be the application of the term genocide which in the domain of international law seems to be the only established term.

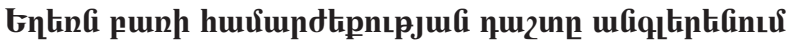

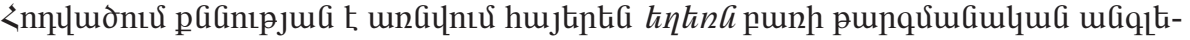

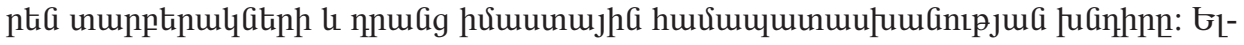

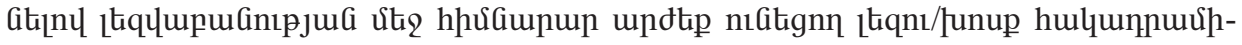

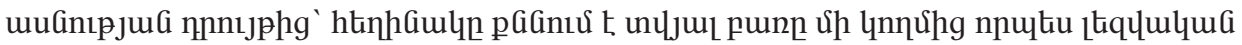

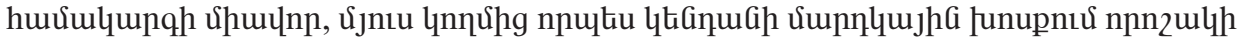

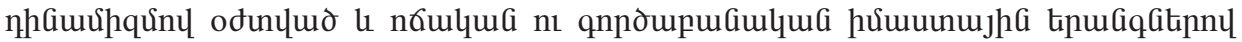

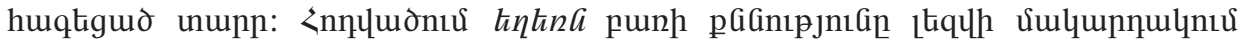

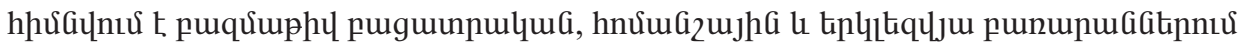

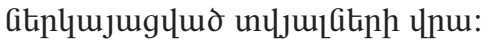

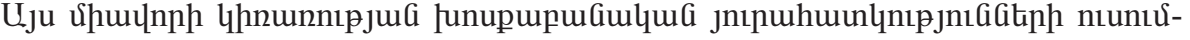

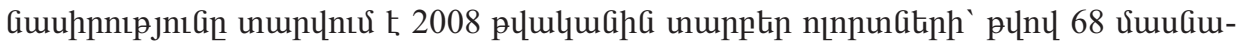

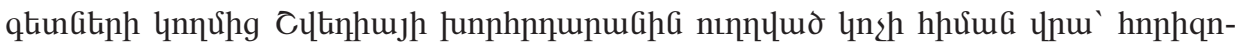

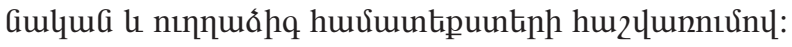

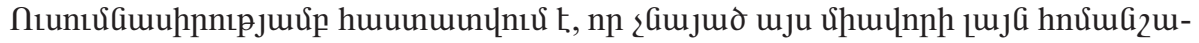

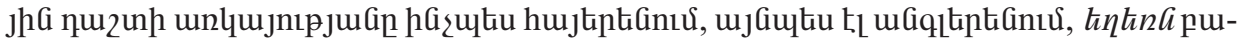

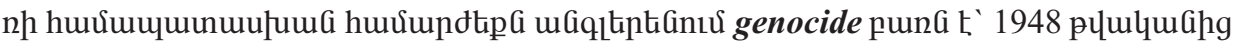

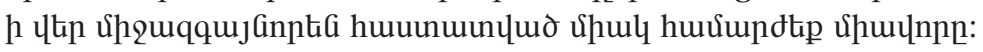

